Michael J. Dueker is a research officer at the Federal Reserve Bank of St. Louis, and Andreas M. Fischer is an economic advisor at the Swiss National Bank, Zürich, Switzerland, and a CEPR Fellow. Nick Meggos provided research assistance. An earlier version of this article appeared in Geld, Währung und Konjunktur, the Quarterly Bulletin of the Swiss National Bank, 1994 no. 4. The authors thank Mathias Zurlinden for many useful comments.

\section{A Guide to Nominal Feedback Rules and Their Use for Monetary Policy}

\author{
Michael J. Dueker and \\ Andreas M. Fischer
}

rentir conomic theory suggests that monetary policy tends to have an inflationary bias when monetary policy is discretionary (Barro and Gordon, 1983). This bias can be eliminated if the monetary authority is able and willing to precommit itself to a policy rule that would ensure price stability in the long run. Although in practice monetary authorities are unwilling to renounce their discretionary powers and adhere strictly to a rule, they still could benefit from using the rule as a guide for policy discussion. Under such an approach, the policy rule provides information that would help make short-run policy decisions consistent with the long-run goal of price stability.

Nominal feedback rules (NFRs), first suggested by McCallum (1987), are one form of policy rules that have recently received considerable attention. ${ }^{1}$ The primary motive for NFRs is to overcome the shortcomings of Friedman's constantmoney-growth rule, which does not take into account changes in the velocity of money. The NFRs are designed such that the monetary authority does not need to rely on a specific model of the economy in order to implement them. The novel feature of the NFR is its feedback mechanism, which specifies precise adjustments in the policy instrument when the nominal target variable deviates from its desired path.

The purpose of this paper is to provide a nontechnical description of NFRs and their use for monetary policy. The recent spate of studies with NFRs primarily has assessed a rule that defines the monetary base as the instrument and nominal GDP as the nominal target; the scope of NFRs permits other specifications, however. NFRs can be used to simulate fluctuations in nominal variables of interest, or to indicate the current stance of actual monetary policy and provide the monetary authorities a reference for setting monetary policy. This survey discusses both uses for NFRs; however, greater attention is given to the indicator model with an empirical illustration for Switzerland.

The indicator model aims to inform policymakers on a timely basis of the likely effect on the baseline rate of inflation of current changes in the policy instrument. The baseline rate of inflation is defined as a backward-looking, shortterm trend rate of inflation. Thus, if unanticipated shocks have raised the baseline rate of inflation, policymakers would like to know if their current actions are geared toward reducing baseline inflation gradually, a course that would not destabilize the real economy and financial markets.

The structure of the paper is as follows: The first section presents a framework for NFRs. The next section reviews normative studies that attempt to show how well NFRs could stabilize the growth of the nominal target variable around its desired path. The third section highlights the use of NFRs as indicator models. These positive exercises demonstrate how the indicator models with nominal feedback can be used as a reference guide for monetary policy. In the final section, we discuss evidence regarding the potential effectiveness of the indicator model as a policy indicator for the Swiss monetary base.
${ }^{1}$ Altermative names for the NFRS are adaptive or McCallum rules; however, throughout the text we will use NFR. 


\section{A FRAMEWORK FOR NOMI- NAL FEEDBACK RULE}

To illustrate the principal features of the NFR, we present a framework that links the instrument variable with the nominal target. The system or policy model is atheoretic and is based completely on lagged information. Three main features make the NFR framework especially useful: First, it defines a long-run target path for the nominal target variable. Second, it incorporates forecasts of the relationship between the policy instrument and the nominal target variable. And, third, it specifies the speed with which policy will adjust in response to a gap between actual and desired levels of the nominal target variable. The generic feedback rule, with all variables in logs, takes the following form:

(1) $\Delta y_{t}=\lambda_{0}-\Delta(x-y)_{t \mid t-1}+\lambda_{1}\left(x^{*}-x\right)_{t-1}$

(2) $\Delta x_{t}^{*}=\lambda_{0}$ for all $t$

Equation 1 represents the NFR and consists of four elements: the policy instrument that the monetary authorities can control, $y_{t}$; the nominal target variable, $x_{t}$; the baseline growth rate for the nominal target variable, $\lambda_{0}$; a forecast of the relationship between the nominal target and the instrument,

$$
\Delta(x-y)_{t \mid t-1} ;
$$

and a feedback parameter, $\lambda_{1}$. Equation 2 defines the baseline level, $x{ }^{*}$, to be a function of the baseline growth rate, $\lambda_{0}$, and the previous baseline, $x_{\mathrm{t}-1}$. The key aspects of Equations 1 and 2 are discussed below in greater detail.

\section{Controllable Instruments}

The NFR assumes that the dependent variable in Equation 1 is a controllable instrument of the monetary authorities. This assumption narrows their choice of instruments to either the monetary base, the exchange rate, or a short-term interest rate. Empirical studies have focused on either the monetary base or the interest rate as the instrument variable. In the empirical illustration of an indicator model for Switzerland, we use the monetary base as the central bank's control variable to conform with the base targeting policy of the Swiss N ational Bank. In many other countries, the central bank uses a short-term interest rate as its policy instrument. The influence of lagged changes in the instrument is not modeled directly in Equation 1, but they may have an indirect influence in the forecasts. Changes in the instrument are dictated by the righthand-side components of the NFR model. Therefore, changes in the instrument, $y_{t}$, are not necessarily associated with changes in the objectives of policy; instead, they may arise from a narrowing or widening of the gap in $\left(x^{*}-x\right)_{t-1}$, or from the forecasted effect of policy actions on the growth of the nominal target variable.

\section{The Role of Forecasts in Feedback Rules}

The models that use NFRs include forecasts of the ratio between the nominal target variable, $x_{t}$, and the instrument, $y_{t}$, to identify the change in the instrument believed to be consistent with the monetary authority's pre-committed nominal target. The forecast provides information regarding both the current instrument setting and accurate forecasts ensure achievement of the current period's desired rate of growth in the nominal target variable:

$$
\text { (3) } \Delta x_{t \mid t-1}=\lambda_{0}+\lambda_{1}\left(x^{*}-x\right)_{t-1} \text {. }
$$

One way to make the forecasts is to take a moving average of

$$
\Delta(x-y)
$$

McCallum (1987) uses this strategy to produce four-year moving average (MA) forecasts of base velocity growth. The attractive feature of the MA forecasts is that they are simple to produce and can be easily verified by the public. Dueker (1993) 
and Thornton (1993), however, show that simulation exercises with Equation 1 are sensitive to the choice of the forecast specification. Dueker (1993) uses an alternative forecasting technique: a time-varying coefficient model with heteroscedastic errors. The primary advantage of forecasts from a time-varying coefficient model, relative to MA forecasts, is that the forecasting information set includes not only past values of the dependent variable, but also a host of explanatory variables. M oreover, the forecasts can adapt to structural breaks in the relationships between the dependent and explanatory variables. The same forecasting method is used in the indicator model of Dueker and Fischer (1996a), which is discussed later in this article.

\section{Feedlback Mechanisms}

The feedback mechanism is defined generally in terms of the long-run nominal target variable. The gap, $x^{*}-\mathrm{x}$, acts as an error-correction mechanism, in that the model allows for corrective feedback when values of $x_{t-1}$ deviate from the baseline value, $x_{t-1}$. As in error-correction models, NFR models are confronted with a trade-off between gradualism and immediate restoration of the target. Small values of the feedback parameter, $\lambda_{1}$, provide little in the way of corrective adjustments. Setting $\lambda_{1}$ equal to zero results in period-by-period targeting of growth in $x_{t}$ at the rate $\lambda_{0}$. Values of $\lambda_{1}$ that are too large, on the other hand, can result in over-correction in the form of explosive oscillations that are dynamical ly unstable. Valid NFRs should not exhibit instrument instability, which is the tendency for the instrument to oscillate explosively. Instrument instability is an important criterion for selecting a feedback parameter, $\lambda_{1}$, especially when the NFR is used for policy simulation. We emphasize, however, that instrument instability presents a problem primarily when an NFR model is simulated as an inviolable rule, rather than used as an indicator model. ${ }^{2}$

An NFR model can achieve a greater degree of realism if it acknowledges that policymakers have multiple objectives to which they do not attach constant weights. If a central bank has more than one objective- say price stability and minimizing uncertainty in financial markets- it is possible to introduce a second feedback mechanism and Equation 1 becomes:

$$
\begin{aligned}
\Delta y_{t} & =\lambda_{0}-\Delta(x-y)_{t \mid t-1} \\
& -\lambda_{1}\left(x^{*}-x\right)_{t-1}+\lambda_{2}\left(z^{*}-z\right)_{t-1} .
\end{aligned}
$$

Dueker and Fischer (1996a,b) consider the case in which a central bank pursues the dual objectives of price and exchangerate stability. In this case, $\lambda_{1}$ and $\lambda_{2}$ represent the feedback parameters in the price and the exchange-rate feedback mechanisms. To add further realism by allowing the importance attached to each objective to change over time, Dueker and Fischer (1996a,b) permit the values of the two feedback parameters to vary over time. In the section on indicator models with nominal feedback, we provide a more detailed discussion of this.

In general, one can think of $z_{t}$ as a variable that receives the attention of the monetary authority over relatively shortrun horizons, after which attention returns to the long-run nominal target, $x$. The case where $x_{t}$ is the price level and $z_{t}$ is some measure of financial-market volatility or imbalance is a good example. The specification of Equation 1 ' itself suggests this ranking of policy objectives: In the long run, all gaps between actual and desired levels will be zero, so the long-run policy goal is to have the nominal target variable, $\mathrm{x}_{\mathrm{t}}$, grow at a rate equal to $\lambda_{0}$.

\section{Revised Baseline Paths}

The model described above may be overly influenced by the assumption that the monetary authority will pursue relentlessly a levels target for $x_{t}$ without making allowances for past surprises, as in Equation 2. One obvious alternative would be to aim for growth in $x_{t}$ at the rate $\lambda_{0}$ period by period, rather than try to correct unexpectedly strong or weak past growth. McCallum (1994) has proposed bridging these two polar cases by

\footnotetext{
${ }^{2}$ The stability conditions for the instruments are not analytically specified in the simulation exercises.
} 
making this period's baseline level for $x_{t} a$ weighted average of last period's actual and baseline levels:

$$
x_{t}^{*}=\lambda_{0}+\delta x_{t-1}^{*}+(1-\delta) x_{t-1}
$$

If $\delta=1$, past surprises always are corrected and never accommodated. On the other hand, if $\delta=0$, they are never corrected and immediately accommodated. Gradual accommodation takes place if $d$ is between zero and one. The accommodation of past surprises is called rebasing.

It may seem preferable to treat all past shocks immediately as bygones, which could be accomplished by setting $\delta=0$. This sort of rebasing has been favored by $\mathrm{McC}$ callum $(1993,1994)$ and Feldstein and Stock (1994) for the following reason: Instrument instability would be reduced for any given value of the feedback parameter, $\lambda_{1}$, and it should be possible to use larger feedback values, implying stronger feedback to the most recent developments, without inducing instrument instability. McCallum (1993) finds in his simulation exercise for Japan that some degree of rebasing $(\delta=0.2)$ can reduce the variance of the nominal target variable around the defined target path. One shortcoming of Equation 2' is that $\delta$ is defined to be constant over time.

\section{POLICY SIMULATIONS WITH NOMINAL FEEDBACK RULES}

The most widely analyzed NFR for policy simulation is $\mathrm{McC}$ allum's rule, in which $x_{t}$ and $b_{t}$ denote nominal GNP and the monetary base for the United States:

$$
\begin{aligned}
\Delta b_{t}= & 0.00739-(1 / 16) \\
& \left(x_{t-1}-b_{t-1}-x_{t-17}+b_{t-17}\right) \\
+ & .25\left(x^{*}-x\right)_{t-1} .
\end{aligned}
$$

The target value of $x_{t}$ is allowed to increase each quarter by 0.00739 , so the target level of nominal GNP increases by 3 percent per year, a rate close to the rate of long-term annual growth in real GNP, in which case average inflation would be approximately zero. The second term acts as a vel ocity forecast, which subtracts a magnitude equal to the average growth rate of base velocity over the previous four years. McCallum (1994) argues that such an average provides a correction for longlasting changes in velocity stemming from regulatory and technological change. Cyclical influences are accounted for by the last term. A stimulative increase in base growth is called for when the previous quarter's level of nominal GNP is bel ow its target value.

To show that McCallum's rule would be able to keep nominal GNP close to a steady target growth path and that the fluctuations around the mean growth rate would be relatively small, McCallum conducts simulations that include shocks in a system consisting of the rule in Equation 3 and an equation depicting the response of $x_{t}$ to the rule-generated values of $b_{t}$ :

\section{(4) $\Delta x_{t}=\alpha_{0}+\alpha_{1} \Delta x_{t-1}+\alpha_{2} \Delta b_{t}+$ error .}

In McCallum's simulation exercises, the monetary base enters directly in the equation for nominal output. Since in macroeconomics there is no agreed-upon model that tracks short-run dynamic behavior of aggregate supply in response to monetary actions, McCallum's strategy is to simulate his rule in Equation 3 with a variety of different models for nominal output, such as in Equation 4. In his study of the U.S. economy, he uses two atheoretic single-equation specifications, several vector autoregressive systems, and three structural models inspired by the real business-cycle theory of Kydland and Prescott, the "monetary misperceptions" theory of Lucas and Barro, and the Keynesian theory based on the Phillips curve.

The simulated root-mean-squared error between nominal GNP and its target level is used to illustrate how application of the rule could stabilize nominal GNP growth. With his simulations for various structural models, McCallum suggests that 
if the Federal Reserve had followed his rule, the United States would have had smaller fluctuations in nominal GNP and would have experienced zero inflation, on average. $^{3}$

International evidence for McCallum's rule is somewhat mixed. Hall (1990) applied McCallum's rule with a feedback value of 0.25 to the United States, Canada, Japan, and Germany. He found that if the United States and Canada had followed McCallum's rule, significant reductions in inflation could have been achieved. In contrast, simulations of the rule for West Germany and Japan indicated that the rule would have increased nominal GNP variability around the trend. Hall's results show that modification of the rule's specification is often needed. One reason for Hall's disappointing results rests on the choice of the feedback value. McCallum (1993) finds that a higher feedback value than 0.25 is needed for Japan.

Judd and Motley $(1992,1993)$ and McCallum (1990a, 1993, 1994) have explored an alternative feedback rule in which the central bank changes the shortterm interest rate in response to divergence between actual and targeted nominal GDP growth rates. These authors specified a short-term interest rate as the instrument, because it is controllable in the short-run and because various central banks, notably the Federal Reserve, have shown a preference over the years for operating through such an instrument rather than a reserves aggregate. The rule examined is specified as follows:

$$
\text { (5) } \Delta R_{t}=\lambda\left(\Delta x-\Delta x^{*}\right)_{t-1} \text { where } \lambda>0 \text {. }
$$

In this equation, $\Delta R_{t}$ is the quarterly change of a short-term interest rate and $\Delta \mathrm{X}_{\mathrm{t}-1}$ is the growth rate in nominal GNP in the preceding quarter. No forecasts are provided as in the monetary base models.

Judd and Motley (1993) simulate the above equation for the United States over the sample 1960-89, a period in which inflation averaged $5 \frac{1}{2}$ percent. They find that when $\lambda=0.2$, inflation could have been held between about zero and 2.5 percent if the interest rate rule had been followed. McCallum (1990a, 1993), on the other hand, finds that the performance of policy rule (5) is poor. Generally, when the feedback values, $\lambda$, are too low, the feedback mechanism provides insufficient corrective stimulus and fails to keep nominal GNP close to the target path. Otherwise, if $\lambda>0.3$, then explosive oscillations occur. Moreover, McCallum finds that the stability of the policy rule in Equation 5 is sensitive across the different models of output. This is a disturbing result since there is no generally accepted model of how nominal variables are generated.

A repeated remark against the simulations performed with NFRs is that they suffer from the Lucas critique, which states that the parameters used to simulate the datagenerating process for nominal variables are calibrated in a world devoid of an NFR, and they would change if an NFR were in effect. This point pertains to the class of normative studies that attempt to make policy statements based on counterfactual simulations. A second type of critique concerns the robustness of the fixed coefficient models such as Equation 4. It is well known that monetary policy must cope with variable lags and that the channels of the transmission mechanism have been altered by innovations in financial services.

\section{INDICATOR MODELS WITH NOMINAL FEEDBACK}

Dueker and Fischer (1996a) suggest that in countries with low average rates of inflation, monetary policy might be welldescribed by an NFR. The claim is that an implicit NFR, especially one with timevarying parameters, can be a good model of past policy and past data. Countries with a high inflation bias, in contrast, are not likely to have conducted monetary policy in a way that is well described by a monetary rule. Such indicator models do not suggest that the monetary authorities have followed an NFR exactly; instead, the NFR indicator model provides information regarding the implicit objectives embedded in past and present policy actions. Thus, the goal of the indicator model is to provide a

\footnotetext{
3 Using the same rule as Equation 3, McCallum (1990b) conducts simulations of a model of the U.S. economy aS it was in the 1923-41 period. The simulation results suggest that a monetary base rule could have prevented the Great Depression if the rule had been in effect.
} 
${ }^{4}$ The Markov process is assumed to be influenced by an unobserved random variable $s_{t}^{*}$, which will be called the state or regime that the process was in at date $t$. If $s_{t}^{*}=0$, then the process is in regime 1 with mean $s_{\mu 1}$, while $s_{t}^{*}=1$ means that the process is in regime 2 with mean $s_{\mu 2}$. Note $s_{t}^{*}$ takes on only discrete values defined by the Markov chain. For a first-order Markov chain with transition probabilities $\left\{p_{i j}\right\}$, the probability that $s_{t}$ equals some particular value $j$ depends only on the most recent value:

$p\left\{s_{t}=j \mid s_{t-1}=i, s_{t-2}=k, \ldots\right\}$ $=p\left\{s_{t}=j \mid s_{t-1}-i\right\}=p_{i j}$

The basic filtering and smoothing algorithms for a Markovswitching model are discussed in Hamilton $(1988,1989)$. guide for monetary policy discussion by illustrating whether current policy actions are geared toward increasing, decreasing, or maintaining the baseline rate of inflation identified by the NFR indicator model.

In the indicator models, the parameters from the NFR are estimated so that we may know the properties of the NFR that best describe past policy. In simulation exercises, in contrast, the parameters are arbitrarily fixed. A further distinguishing feature of the NFR-indicator models is that the coefficients can be time-varying and, therefore, the model is able to adapt to shifts in the weights given to alternative objectives. For example, in small open economies, it is likely that the rate of domestic price inflation cannot al ways be the overriding policy objective. At times, the exchange rate can become the focus of monetary policy when shocks push it out of line with fundamentals. Thus, it is important that the indicator model permits shifts in the feedback parameters that reflect shifts in the weights attached to alternative policy objectives.

Dueker and Fischer (1996a,b) have constructed NFR indicator models that allow the parameters to vary over time via Markov switching. Their nominal-feedback model takes the form

(6)

$$
\begin{aligned}
\Delta b_{t} & =\lambda_{0 t}+\Delta(b-p)_{t \mid t-1}+\lambda_{1 t}\left(p^{*}-p\right)_{t-1} \\
& +\lambda_{2 t}\left(e^{*}-e\right)_{t-1}+\varepsilon_{t} .
\end{aligned}
$$

Baseline Price Path:

$$
p_{t}^{*}=\lambda_{0 t}+\delta_{1 t} p_{t-1}^{*}+\left(1-\delta_{1 t}\right) p_{t-1} .
$$

Baseline Exchange Path:

$$
e_{t}^{*}=e_{0 t}+\delta_{2 t} e_{t-1}^{*}+\left(1-\delta_{2 t}\right) e_{t-1} .
$$

All of the coefficients are subject to change according to a Markov-switching process. ${ }^{4}$ For application to Switzerland, the monetary base is the policy-instrument variable. Equation 6 implies that expected inflation in any period equals the baseline rate, $\lambda_{0}$, plus possible adjustments due to the gap between the baseline and actual price levels, $\left(p^{*}-p\right)_{t-1}$, and to the gap between the baseline and actual exchange rates, $\left(e^{*}-e\right)_{t-1}$. The baseline rate of inflation, $\lambda_{0}$, is defined as the backward-looking, short-term trend rate of inflation. This interpretation of the time-varying parameter $\lambda_{0}$ reflects the persistence in price inflation. Once unanticipated shocks have raised or lowered the inflation rate, it will remain above or below normal for some time so that policy actions can only gradually adjust the baseline inflation rate.

Equations 7 and 8 define the baseline paths for prices and the exchange rate to be a weighted average of last period's baseline and actual values plus trend growth. Such revisions of the baseline occur for values of $\delta<1$. Consequently, shifts in the baseline path are gradually accommodated. As $\delta$ decreases from one, the rate of accommodation increases.

\section{AN INDICATOR MODEL FOR THE SWISS MONETARY BASE: AN EMPIRICAL ILLUSTRATION}

This section illustrates an application of the indicator model of Dueker and Fischer (1996a), which is outlined in the previous section. The purpose of this exercise is to explain variation in the rate of monetary base growth for Switzerland by estimating changes in the baseline rate of inflation and the baseline exchange rate. The model's results will help us answer such questions as whether a shift in base growth appeared to stem primarily from inflation factors, exchange-rate considerations, or a shift in base velocity. The model, which uses the monthly growth in the Swiss monetary base as the instrument variable, is estimated for the period 1972:1 through 1987:12. The primary policy objective is assumed to be domestic price inflation, as measured by the consumer price index. The exchange rate, as measured by the 
Swiss franc-Deutsche mark rate, is treated as the second policy objective. As a test of model robustness, we use the parameters estimated from the 1972:1-1987:12 period to examine the out-of-sample behavior of model-implied money growth for the period 1989:7-1994:4. An 18-month gap (1988:11989:6) between the in-sample and the out-of-sample observations remains, because the monetary base experienced a permanent shock affecting reserves demand beginning in January 1988. The shock to reserve demand stemmed from two sources: a reduction in reserve requirements and the introduction of the Swiss Interbanking Clearing $(\mathrm{SIC})$ system. During this transition period, reserves fell from a peak of 10 to three billion Swiss francs. If the model parameters from the 1970s and 1980s remain useful for analyzing Swiss money growth following this shock, then the indicator model is relatively insensitive to regulatory changes and financial innovations in the payments system.

Estimates of the baseline inflation path for Switzerland reveal an average rate of 2.4 percent per year from 1972 to 1987. Because the feedback parameter for prices, $\lambda_{1}$, is small, monetary base growth between 1973 and 1987 appeared to respond primarily to expected changes in base velocity, variation in the baseline inflation rate, and occasionally to the gap between actual and baseline exchange rates. Figure 1 plots a one-year moving average of inflation in Switzerland, a one-year moving average of the modelimplied baseline inflation rate, and the yield on long-term government bonds in Switzerland. It shows that the model-implied baseline inflation rate corresponds better than actual inflation to changes in the government bond rate. The relatively close match between movements in the baseline inflation rate and the government bond rate suggests that the baseline inflation rate provides a useful estimate of the underlying trend rate of inflation, which is the most important factor in determining the yield on long-term nominal bonds.

It is also interesting to examine periods when relatively large gaps developed between actual and baseline inflation in Figure 1.

\section{Figure 1}

One-Year Moving Averages of Inflation and the Model-Implied Target Plotted with Long Bond Rate

Percent

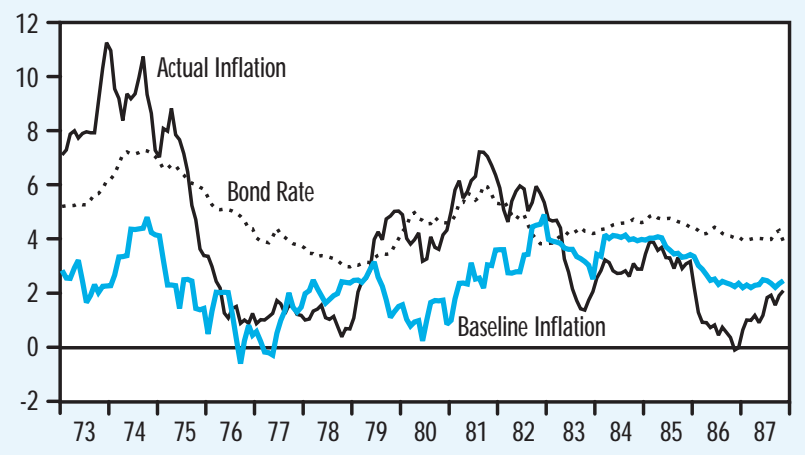

The first oil shock in 1973-74 sent inflation to a level well above the baseline rate, as one might expect from a supply shock. A second oil shock in 1979 led to a similar but smaller positive gap between actual and baseline inflation. Throughout the 1970s, Switzerland's main trading partners tended to experience even greater inflationary pressures, so that the Swiss franc tended to appreciate, a situation which led monetary policymakers to be concerned with the exchange rate on several occasions. A positive supply shock pushed actual inflation bel ow the baseline rate in 1986 when oil prices fell substantially. As the baseline trend would predict, however, actual inflation returned to the baseline rate within a relatively short period.

Figure 2 plots the model-implied feedback parameter for the exchange-rate gap, $\lambda_{2}$. The model identifies three periods when monetary policy appeared to respond to the exchange rate in the 1970s. The first period in 1972 corresponds with the tail end of the Bretton Woods system of generally fixed exchange rates. The second period saw relatively minor exchange-rate feedback in 1974-75 and came on the heels of the first oil shock. The third period, which saw the greatest amount of exchange-rate feedback to base growth, was 1978-79. By 1978 the Swiss franc had appreciated significantly against 


\section{Figure 2}

Probability-Weighted Feedback Parameter on the Exchange-Rate Gap

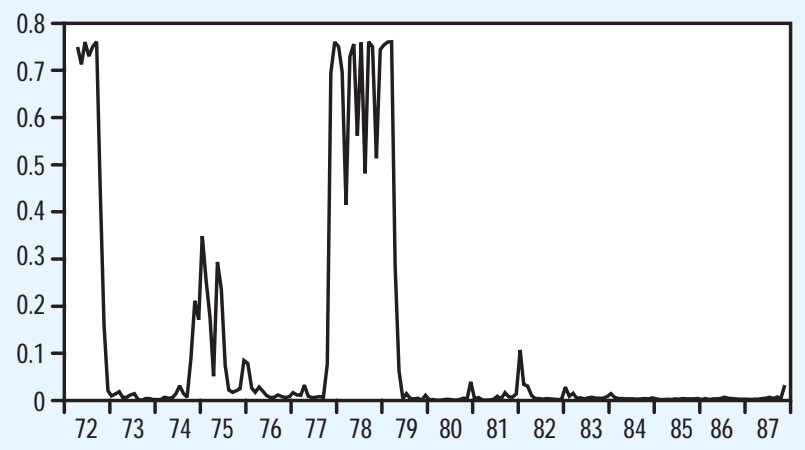

\section{Figure 3}

One-Year Moving Averages of Inflation and the Model-Implied Target Plotted with Long Bond Rate

Percent

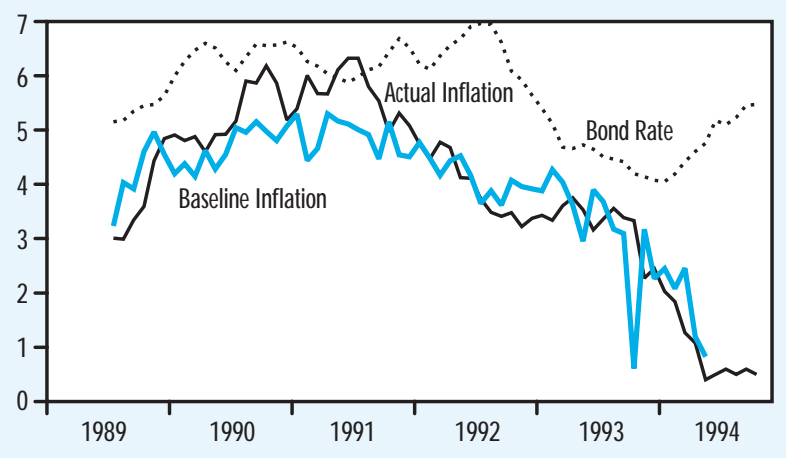

the Deutsche mark, and policymakers became concerned about possible harm to the real economy brought by the high real exchange rate. Thus, throughout 1978 base growth was increased in response to the desire to dampen the appreciation of the Swiss franc. As the risk of inflation increased, and the Swiss franc began to depreciate, monetary policy renewed its focus on price stability in early 1979 . The model does not detect any significant exchange-rate feedback to base growth since 1979.

To see if the indicator model provides useful information in an out-of-sample con- text, which is where real-world policy decisions must be made, we use the model estimated with data from 1972-87 to analyze data from the 1989:7-1994:4 period. Figure 3 updates Figure 1 with plots of a one-year moving average of actual inflation, the modelimplied baseline inflation rate, and the government bond rate. The chart shows that actual inflation and the model-implied baseline rate moved more closely together in the 1990s than in the 1970s and 1980s.

It appears that external supply shocks have not played a large role in creating wedges between the baseline rate and actual inflation in the 1990s. Interestingly, the model-implied baseline inflation rate accelerated from a little more than 3 percent to almost 5 percent between July and November in 1989. Thus, the indicator model signalled a clear build-up in inflationary pressures at a time of considerable uncertainty regarding base demand. With respect to the disinflation that began in 1991, the indicator model closely matches the gradualist movements of actual inflation. By mid-1994, the model-implied baseline inflation rate had descended to slightly less than 1 percent, which is, for all practical purposes, price stability, given the well-known slight upward bias in the consumer price index. The government bond rate, in contrast, has followed the global trend by increasing, on average, since late 1993, despite the fact that inflationary pressures have remained subdued in almost all major economies.

\section{CONCLUSIONS}

Nominal feedback rules were developed in response to the apparent shortcomings in constant-money-growth rules and to the inflationary bias in purely discretionary monetary policy. McCallum has argued that monetary policy based on his rule is more likely than a constant-money-growth rate rule to achieve the fundamental economic goal of price stability, because the feedback mechanism is able to produce stronger countercyclical effects on aggregate demand and is able to guard itself against the consequences of financial and regulatory changes. However, because it appears that monetary 
authorities are as unlikely to relinquish their discretionary powers to an NFR as they were to constant-money-growth rules, a more promising avenue for NFRs is their use as indicators for monetary policy. Rather than stating that policy should follow a specific, inviolable rule, indicator models with nominal feedback can be used as a reference guide. As highlighted in the previous section, the indicator model allows the monetary authorities to consult the recommendations of an NFR-indicator model when analyzing current monetary conditions.

To illustrate the use of an NFR-indicator model as a useful policy tool, we sketch the results from Dueker and Fischer (1996a) concerning Swiss monetary policy. The NFR-indicator model provides a useful estimate of the baseline inflation path embedded in recent decisions concerning base growth. We show that the baseline inflation path matches fairly well with shifts in the Swiss government bond rate, which is recognized generally as an important inflation bellwether. Hence, by referring to an NFR-indicator model, policymakers have a tool that is independent of market expectations to help them understand the signal they are sending financial markets regarding the inflation outlook.

\section{REFERENCES}

Barro, Robert J., and David B. Gordon. "A Positive Theory of Monetary Policy in a Natural Rate Model," Joumal of Political Economy (August 1983), pp. 589-610.

Dueker, Michael J. "Can Nominal GDP Targeting Rules Stabilize the Economy?" this Review (May/ June), pp. 31-40.

Dueker, Michael, and Andreas M. Fischer. "Inflation Targeting in a Small Open Economy: Empirical Results for Switzerland," Journal of Monetary Economics (February 1996a), pp. 89-103.

\footnotetext{
_. _ _ _ . "Do Inflation Targets Redefine Central Bank Inflation Preferences? Results from an Indicator Model," in Koos Alders et al., eds., Monetary Policy in a Converging Europe, Amsterdam: Kluwer, 1996b, pp. 21-37.

Feldstein, Martin, and James H. Stock. "The Use of a Monetary Aggregate to Target Nominal GDP," Monetary Policy. Studies in Business Cycles. Vol. 29. N. Gregory Mankiw,ed., University of Chicago Press, 1994, pp. 7-62.
}

Hall, Thomas E. "McCallum's Base Growth Rule: Results for the United States, West Germany, Japan and Canada," Weltwirtschaftliches Archiv, 1990, pp. 630-42.

Hamilton, James D. "Rational Expectations Economic Analysis of Changes in Regime: An Investigation of the Term Structure of Interest Rates," Journal of Economic Dynamics and Control (J une/ September 1988), pp. 385-432.

. "A New Approach to the Economic Analysis of Nonstationary Time Series and the Business Cycle," Econometrica (March 1989), pp. 357-84.

Judd, John P., and Brian Motley. "Controlling Inflation with an Interest Rate Instrument," Federal Reserve Bank of San Francisco Economic Review (3, 1992), pp. 3-22.
"Using a Nominal GDP Rule to Guide Discretionary Monetary Policy," Federal Reserve Bank of San Francisco Economic Review (3, 1993), pp. 3-11.

McCallum, Bennett T. "The Case for Rules in the Conduct of Monetary Policy: A Concrete Example," Federal Reserve Bank of Richmond Economic Review (September/ October 1987), pp. 10-18.

. "Targets, Indicators, and Instruments of Monetary Policy," Monetary Policy for a Changing Financial Environment," W. Haraf and W. Cagan, eds., AEl Press, 1990a.

. "Could a Monetary Base Rule Have Prevented the Great Depression?" Journal of Monetary Economics (August 1990b), pp. 3-26.

. "Specification and Analysis of a Monetary Policy Rule for Japan," Monetary and Economic Studies (November 1993) Bank of Japan, pp.1-45.

. "Monetary Policy Rules and Financial Stability," NBER Working Paper №. 4692, 1994.

Thornton, Saranna R. "Can Forecast-Based Monetary Policy be More Successful than a Rule?" Joumal of Economics and Business (AugustOctober 1993), pp. 231-45. 